\title{
USE OF WIKIS AS A COLLABORATIVE ICT TOOL FOR EXTENDING THE FRONTIERS OF KNOWLEDGE IN TERTIARY INSTITUTIONS
}

\section{ESTHER F. FOMSI AND ELLA THOMPSON GOGO}

(Received 21, December 2016; Revision Accepted 23, February 2017)

\begin{abstract}
The human brain works much like a network of computers connected by nodes. These nodes allow computers on the same network to communicate effectively. Educators have discovered that today's learning environment functions much the same way, with learners connecting to the internet, to other learners and to their teachers to increase their knowledge. This discovery has led to a paradigm shift in education which has transformed the learning environment from teacher-centered to learner-centered. The learner-centered environment allows for interactivity, communication and collaboration. When Web 2.0 technologies are used in the classroom, learners and teachers are given the opportunity to extend the frontiers of knowledge by collaborating and contributing to knowledge. This paper explores the possibility of using Wikis - a Web 2.0 technology - to extend the frontiers of knowledge. It also discusses how Wikis are presently being used in education; how to create a Wiki site using three different Wiki host platforms; and how to contribute content to Wikipedia - which is the world's largest Wiki site. Finally, recommendations are given on what management of institutions can do to encourage the use of Wikis in the classroom.
\end{abstract}

KEYWORDS: Collaboration, Web 2.0 technology, Wikis, Wikipedia, $21^{\text {st }}$ century skills, Frontiers of knowledge

\section{INTRODUCTION}

Human society has experienced several transformations over the years which has affected human activities. According to Toffler (1980), these transformations are waves of development. The three waves of human development described by Toffler, have seen man migrating from one form of society to another. In the first wave, man operated largely an agrarian society where agriculture was the main stay. The second wave was an industrial age society which saw the industrial revolution spreading across the world. The third wave is the information age. One very interesting feature of the $21^{\text {st }}$ century (Information age) is information explosion, which is made possible by technology.
This technology allows for collaboration, which is one of the $21^{\mathrm{st}}$ century skills that works together with the other C's (Communication, Creativity and Critical thinking).Collaboration, according to Longman Dictionary (2015), means to work together with a person or group to achieve something. This means team work among team members or different set of teams. Collaboration opposes learning and productivity in isolation (Ken, 2014). Computers, smart phones and the internet have created room for access to information, however, the tools available for content creation and sharing has to be harnessed to make meaningful collaborative efforts and more organized knowledge expansion.

The educational process exists to preserve, transfer and expand knowledge/culture.

Esther F. Fomsi, Department of Curriculum Studies/Educational Technology, Faculty of Education, University of Port Harcourt, Rivers State, Nigeria.

Ella Thompson Gogo, Department of Curriculum Studies/Educational Technology, Faculty of Education, University of Port Harcourt, Rivers State, Nigeria. 
And technology exists to ease this process. The $21^{\text {st }}$ century classroom calls for a paradigm shift in the different components of teaching and learning; from teacher-centered learning environment to learner-centered learning environment; redefinition of teachers' role from the saga-on-the-stage to the guide-on-the-side; from the dispenser of knowledge to facilitator of learning and many other components (UNESCO,
2002). Technology has come to stay, is growing and providing various tools that can support faculty to enhance teaching/learning and ease the transition from the old paradigm to the new. It therefore becomes necessary for faculty to be aware of what technologies are available and what their affordances are. One of such is Wikis. Table 1 presents these components and the shifts.

Table 1: Paradigm shift in learning environment

\begin{tabular}{|c|c|c|}
\hline & $\begin{array}{l}\text { Teacher-centred learning } \\
\text { environments }\end{array}$ & $\begin{array}{l}\text { Learner-centred } \\
\text { learning environments }\end{array}$ \\
\hline Classroom activity & Teacher-centred, Didactic & Learner-centred, Interactive \\
\hline Teacher role & Fact teller, Always expert & Collaborator, Sometimes learner \\
\hline Instructional emphasis & Facts' memorization & $\begin{array}{l}\text { Relationships, Inquiry and } \\
\text { invention }\end{array}$ \\
\hline Concepts of knowledge & $\begin{array}{l}\text { Accumulation of facts, } \\
\text { Quantity }\end{array}$ & Transformation of facts \\
\hline Demonstration of success & Norm referenced & Quality of understanding \\
\hline Assessment & Multiple choice items & $\begin{array}{l}\text { Criterion referenced, Portfolios } \\
\text { and performances }\end{array}$ \\
\hline Technology use & Drill and practice & $\begin{array}{l}\text { Communication, access, collabo- } \\
\text { ration, expression }\end{array}$ \\
\hline
\end{tabular}

Source: UNESCO (2002) Information and Communication Technologies in Teacher Education

The first thing to note about Wikis is that it is a Web 2.0 technology that is centered on collaboration and information sharing. Web 2.0 is the second generation of the World Wide Web (WWW) which focuses on collaboration and information sharing and is a major characteristic of constructivism in group dynamism. A Wiki is a website that allows anyone who has access to the site to edit the contents using just the web browser (Marina, 2013). The right to edit a given Wiki site is only by registered persons in the given Wiki site. It is worth mentioning here that the largest Wiki site is the famous Wikipedia (Wikipedia, 2016).Wikipedia is a free encyclopedia, written collaboratively by various contributors who are registered. Many people are constantly improving Wikipedia, making thousands of changes per hour, thus extending the frontiers of knowledge. The use of Wikis in Nigeria by faculty and students is not at a high level when compared to other countries. Some research findings point towards Nigerian students being slightly enlightened about the use of Wikis, but not so much about faculty. Furthermore, majority of these findings are only based on selfreports rather than actual observation or participation (Akorede, Okunlaya, 2015 and Eberechi 2016).

\section{The Problem}

The $21^{\text {st }}$ century classroom calls for a paradigm shift in the different components of teaching and learning; from teacher-centered learning environment to learner-centered learning environment; redefinition of teachers' role from the saga-on-the-stage to the guide-on-the-side; from the dispenser of knowledge to facilitator of learning and many other components. (UNESCO, 2002). However, despite the paradigm shift, most members of faculty in our tertiary institutions in Nigeria still see themselves as the sole possessor of knowledge. They still exercise a lot 
of influence on choosing content that should be taught, type of learning that should take place, and textbooks that should be used by learners. They do not leverage the opportunities provided by technologies such as Wikis in extending the frontiers of knowledge and transforming the learning environment. A possible reason for this could be a lack of knowledge of the affordances of Wikis and skills to create and use Wikis.

The purpose of this article therefore is to explain the use of Wikis as a collaborative ICT tool for extending the frontiers of knowledge in tertiary institutions.

The specific objectives are to:

1. Discuss what Wikis are.

2. Describe how Wikis are presently being used in education

3. Explain how to create a Wiki site using three different Wiki host platforms, and;

4. Illustrate how to contribute content to Wikipedia - which is the world's largest Wiki site

5. Explain how Wikis can be used to extend the frontiers of knowledge

\section{Wikis - What are they?}

The nature of Wikis has evolved over time. The history of Wikis dates back to 1994 when Ward Cunningham developed the first Wiki software which he named WikiWikiWeb. The initial intention was ease of communication among web developers using hyperlinks, but like most technologies, the observed outcome usually exceeds the expected outcome. This is made possible by the creative minds of individuals that interact with these technologies. Wikipedia, which is now the world's largest Wiki site is a free content encyclopedia which was released in 2001. There are thousands of Wiki websites and the opportunity to create more is still open, so one can only imagine what the future holds. Not up until 2001, the use of Wikis was restricted to computer programmers. Even when Wikipedia was first introduced in 2001, the procedure for collaborative effort was really tasking; articles were from very highly qualified contributors (one can imagine the screening), and then the articles will go through thorough peer-review which delays the process alongside pending mailing list of interested editors. From just the initial smallscale web-based communications on Wikis, conferences were organized. The first of which was called Wikimania and organized in 2005 at
Frankfurt, Germany and later on other conferences.

A lot of people have added their bits of spices to what Wikis are, based on their experiences with Wikis. Generally speaking, a Wiki is a website which allows anyone who has access to the site to edit the contents using just the web browser. According to Alexander (2006) as cited in Foley and Chang (2016), Wikis supports micro-content creation, supports the ideology of "wisdom of the crowds" and collective authoring/participatory webbing. Lori (2016) also agrees to Wikis supporting collective wisdom for content creation. Foley and Chang (2006) stated that professional development is another use of Wikis in education. Below are some characteristics that describe Wikis:

- It is a webpage that has an edit button.

- Allows users (registered) to edit the content of the site.

- Allows for collaboration which embraces the concept of "wisdom of crowds".

- Allows the use of links to connect related pages together.

- The content can be accessed anytime and from anywhere.

- Keeps a history of what is been add to the site and who is adding.

- It can be customized to get notification once any change is made on the site.

- A Wiki site can be created by anyone who is interested.

To add, remove or modify contents to a Wiki site, three activities are required: click on the edit button, write the content, save the content. Links are used to connect related Wiki sites so as not to crowd up a particular site. (Lee, 2007)

\section{How Instructors Use Wikis}

With Wikis, like many other kinds of technology, the application depends on the creative mind of the user. While some use Wikis minimally; others are maximizing it to the fullest ways their minds can conceive. Wikis are resourceful for teachers and students. Below are some possible uses of Wikis, however, the titles of the Wiki sites are not included.

- To create an online text for the classroom.

- To engage students through the publication of their works and ideas on the Wiki site created. 
- To create an online presence for a school.

- To create digital portfolios for students and faculty.

- To create collaboration among classes, schools and even extend it to include users around the world.

- For capturing lecture.

- Used to maintain a repository for class files where each student has a page and uploads their work for assessment and also download works given by the teacher.

- Teachers use pages as a type of lesson plan and share them with students each week. It actually proved effective for tracking lesson progress and served as a resource material for students.

- Students and faculty maintain Wiki account to use for links and other kinds of small projects.

- Students collaborate with students from other countries to build a Wiki.

- Students use a Wiki site to communicate, share ideas, and also discuss issues.

- Wikis used as information portal for parents, students and faculty.

- Wiki is used to gather the writing of students in classrooms around the world. Students publish a "story of their world" and are also involved in peer reviewing one another's work.

- Wiki is used to merge two or more actual real classrooms virtually into one large classroom.
- Students were given the opportunity to represent themselves as a chemical element and use a page in the Wiki to describe themselves.

From the experiences shared above, students, faculties, school administrators and even parents are involved.

\section{How to create a Wiki site}

Wikis provide enormous opportunities for all levels of education: from kindergarten to tertiary level. The major experience with Wikis is centered on creating a Wiki site and using it. The idea of creating a Wiki site is not as scary as it sounds; the process is similar to filling a very short form. In this section, three Wiki host sites (platforms) that can be used to setup a Wiki site will be reviewed. These are Wikispaces, pbworks and wetpaint. The Edit button activates the editing window to add or edit content and is usually similar to Microsoft Word.

\section{Wikispaces}

This site is available for faculty and students who want to create a Wiki space for educational purposes. Link up for free using http://www.Wikispaces.com/content/classroom and it will lead to the environment in figure 1. Fill in information for Username, Password and Email as illustrated in figure 2. Click on Create Classroom. Finally, follow the simple instructions for the registration process. It is important to make use of the information that can be easily remembered as it will be needed for signing in some other time.

\section{The world's best Wiki platform}

To start select the type of wiki you will create

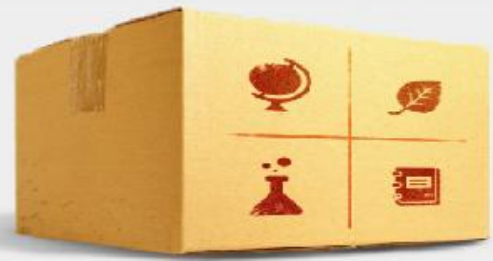

Education
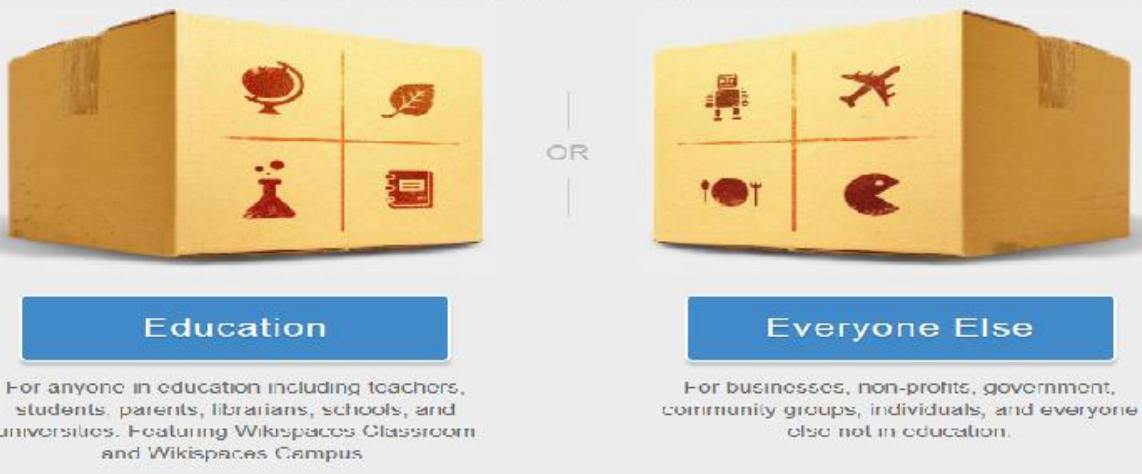

Everyone Else

for busincsscs, non-profits, govornmont: cormunily gioups, individuals, atid everyorie communily gioups, individuals, atid
clise nol mi coducation.

Figure 1: Wikispaces website (Source: www.Wikispaces.com) 


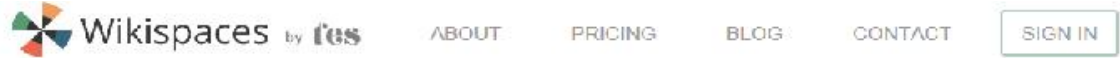

\section{Wikispaces Classroom}

Get your students excited about learning in a modern, easy-to-use environment with the web tools they know and love

Wikispaces Campus

If you're an administrator looking to provide wikis to an entire school, district, or university, you want Wikispaces Camous.

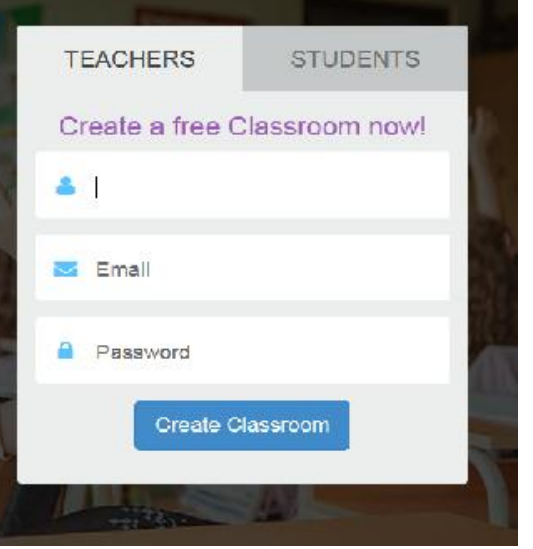

Figure 2: Wikispaces signup page (Source: www.Wikispaces.com/content/classrom)

\section{Pbworks}

This is another site available to businesses as well as education. Link up for free or a fee depending on the choice using http://www.pbworks.com and it will lead to the environment illustrated in figure 3 . Click on the most suitable option and follow the instructions for the registration process (as seen in figures 46 ). It is important to make use of the information that one can easily remember as it will be needed for signing in some other time.

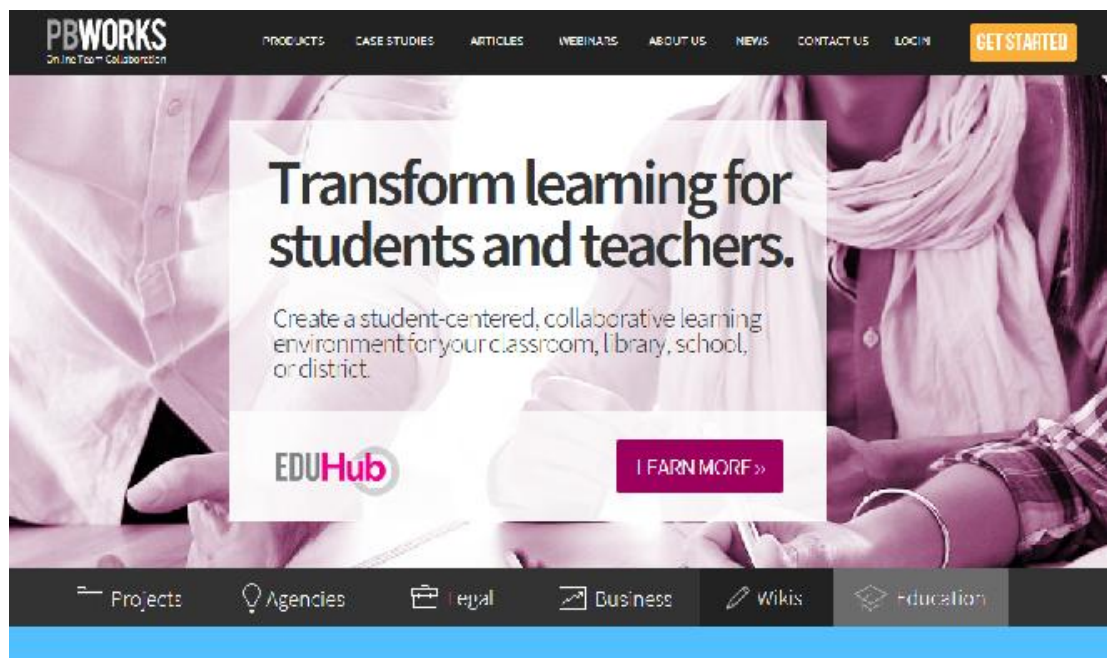

Figure 3: Pbworks Environment (Source: www.pbworks.com) 


\section{Get Started for Free!}

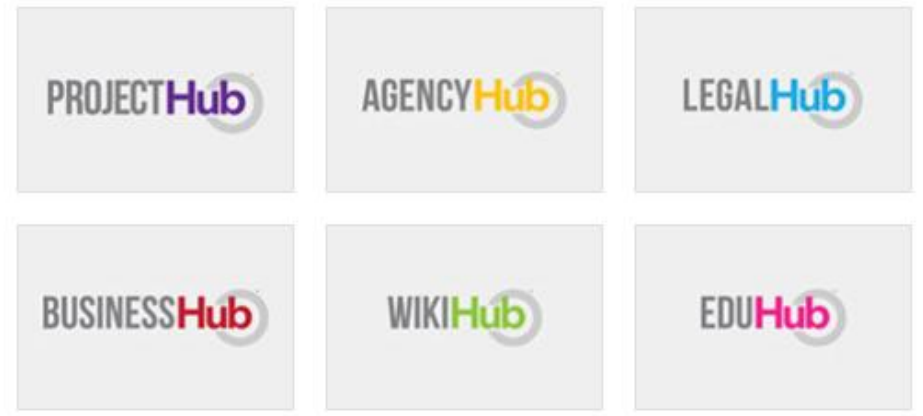

Figure 4: Pbworks options (Source: www.pbworks.com/content/classroom)

Next, choose a suitable plan

\begin{tabular}{|c|}
\hline Campus \\
\hline $\begin{array}{l}\text { School Districts } \\
\text { College Campuses } \\
\text { Library Systems }\end{array}$ \\
\hline Unlimited workspaces \\
\hline 1000 users \\
\hline 40GB storage \\
\hline $\begin{array}{l}\text { Full customization } \\
\text { " learn mcre \& }\end{array}$ \\
\hline $\begin{array}{l}\text { Classroom Accounts } \\
\text { Priority email support } \\
\text { Zip data export }\end{array}$ \\
\hline SELECT $~ *$ \\
\hline
\end{tabular}

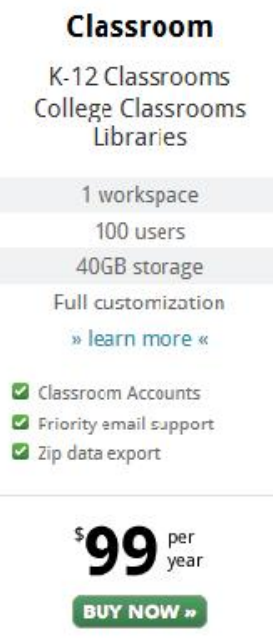

\section{Basic}

Hobbyists \& Clubs

Personal Use

Productivity

1 workspace

100 users

$2 \mathrm{~GB}$ storage

Limitcd customization

" learn more a

Classrcom accounts

Dasic email support

$\boldsymbol{\otimes}$ No data export

\section{FREE}

\section{SELECT *}

Upgrade any time

Figure 5: Pbworks options cont'd (Source: www.pbworks.com)

Click on the next button to fill in more information (see figure 7) and follow the directions to the end. 


\section{PBWORKS}

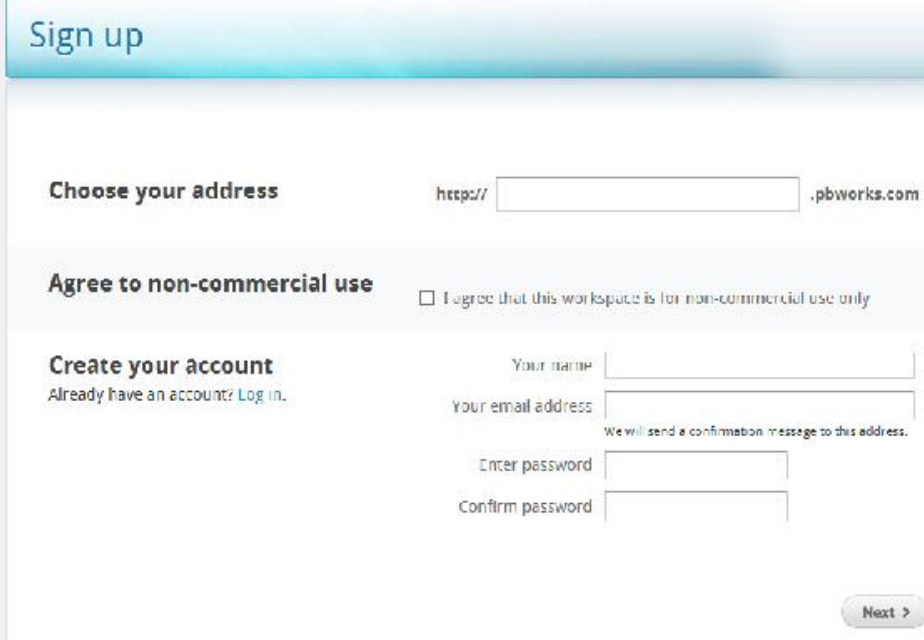

Figure 6: Pbworks signup page (Source: www.pbworks.com/signup)

\section{Wetpaint}

This is another site available for entertainment as well as education. Link up for free or a fee depending on the choice using http://www.wetpaint.com and it will lead to the environment in figure 7 . The sign up/registration process can be completed in three steps (as illustrated in figures 8-10). It is important to make use of the information that can easily remember as it will be needed for signing in some other time.
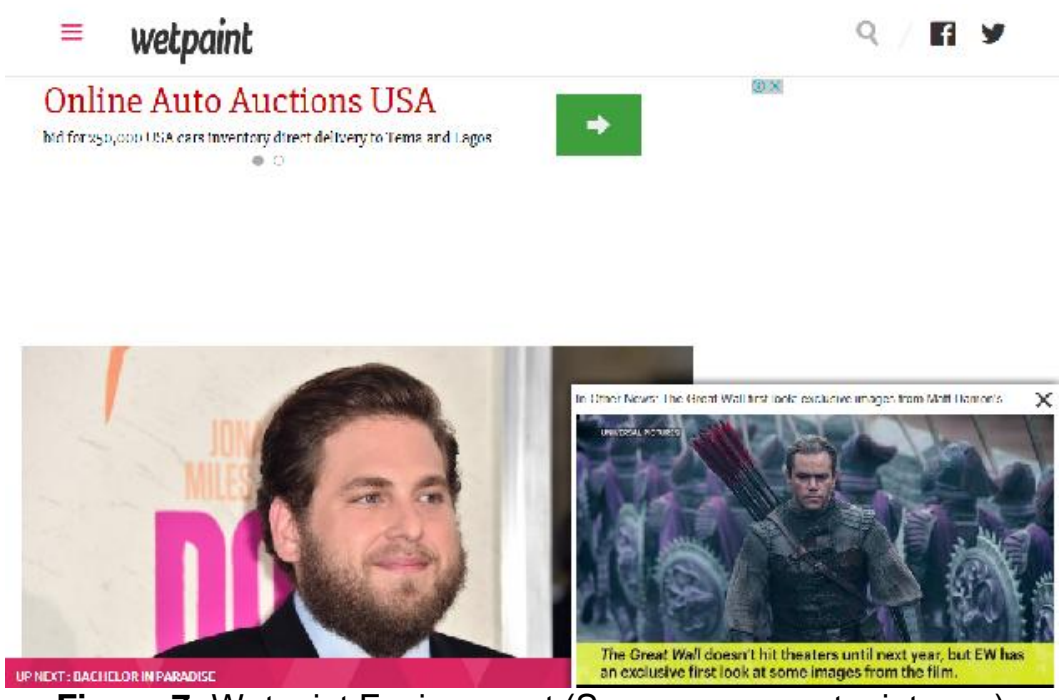

Figure 7: Wetpaint Environment (Source: www.wetpaint.com) 
The first step is to name and describe the Wiki. (As seen in figure 8).

1. name and describe your wiki

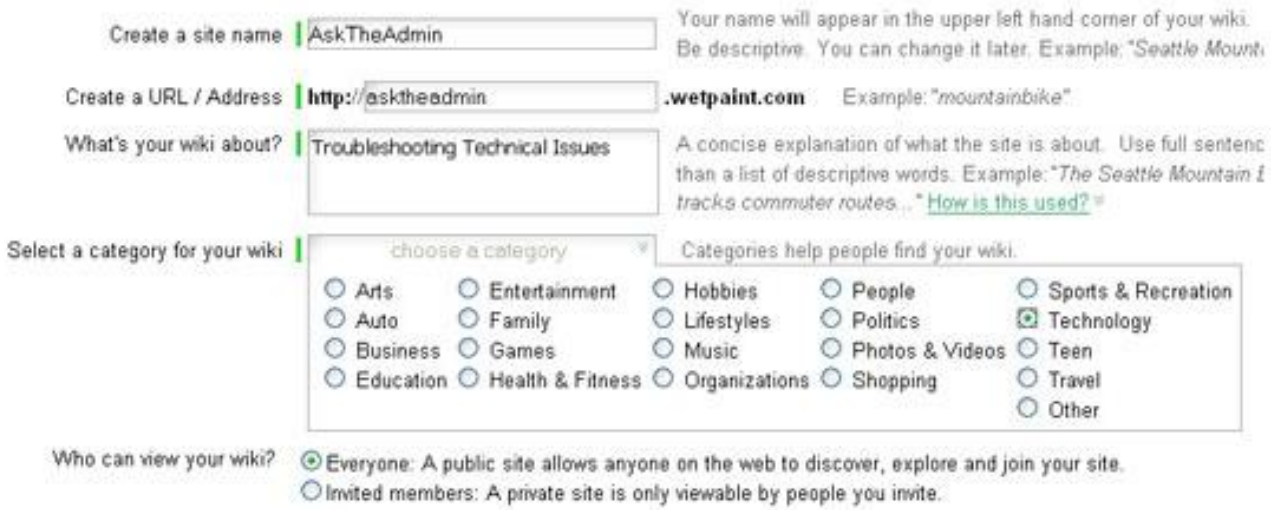

Figure 8: Wetpaint registration step 1 (Source: www.wetpaint.com)

The second step is to specify who can edit the Wiki. (As seen in figure 9).

2 . tell us who can edit your wiki (you can chango it later)
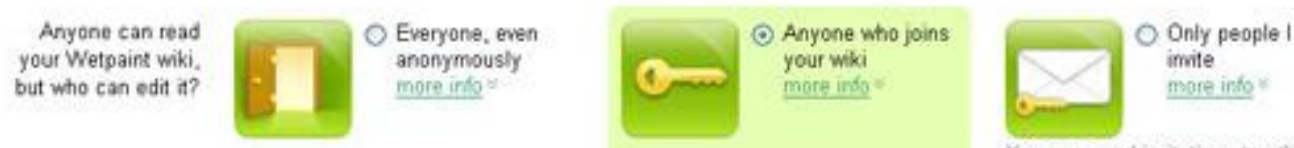

You can send invitations to others 31 the end of this process

Figure 9: Wetpaint registration step 2 (Source: www.wetpaint.com)

The third step is to choose a style for the appearance of the Wiki site. (As seen in figure 10).

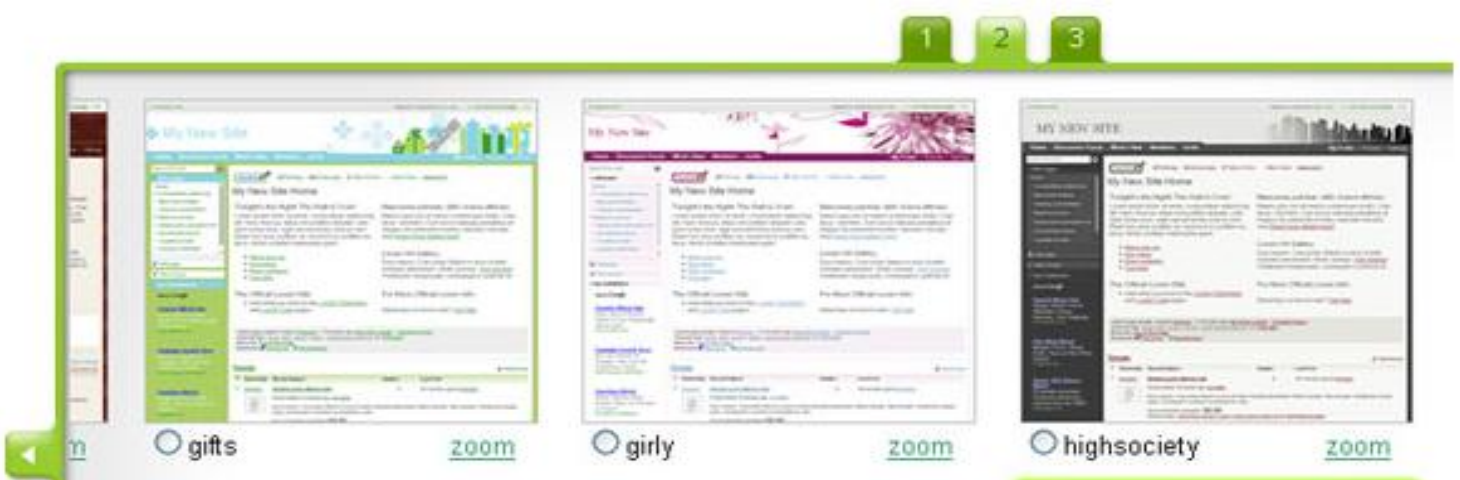

Figure 10: Wetpaint registration step 3 (Source: www.wetpaint.com) 
Wikis can be created for virtually any topic of interest including Wikis and how to use Wikis. One very essential way of exploring technologies is through shared experiences; therefore, the next section is a Wiki resource for faculty on useful and functioning tips for using Wikis.

\section{Wikis as a Resource for Faculty}

- Classroom 2.0 - A Wiki site that provides wealth of links and ideas as well as announcements for upcoming educational programs.

- $\quad$ Educational Origami - A Wiki site that provides resources around the use of higher order thinking in the classroom.

- EducationChannel - A Wiki site that provides ideas and links to Wikis in education.

- $\quad$ ePlanks - A Wiki site that contains lots of practical resources and ideas of Wikis for classroom use.

- $\quad$ edhouse - A Wiki site that provides links and resources for the classroom.

- $\quad$ techLearning-Wild about Wikis- A Wiki site that discusses the value of Wikis and how they can take teachers and student collaboration to the next level. It also includes links to real Wikis created by teachers.

- Web 2.0 in Education - A Wiki site that provides teachers with a directory of free webtools alongside some suggestions as to how they may be used in the classroom.

- Weblogged Wiki- A Wiki site that provides a comprehensive overview of Web 2.0 applications in the classroom.

- Wiki35 - A Wiki site that discusses ways Wikis can be used.
- Wikis in Education - A Wiki site that provides an overview of Wikis and discussions on their use in education, alongside links to articles and examples of Wikis used in education.

These are only few of the numerous resources. As you dig in, you will be exposed to more and more resources through links.

\section{Wikipedia: How to Contribute}

We have already established the idea that anyone can contribute to a Wiki website; and that includes you. In this section, we will demonstrate how to contribute content to the world's largest Wikis site; Wikipedia. Below are the steps:

1. Open your web browser e.g. Mozilla Firefox, internet explorer etc.

2. Type www.Wikipedia.org into the address bar, click on the desired language (e.g. English). (Figure 11)

3. If you already have an account, then simply enter your username and password to $\log$ in, else, click on join Wikipedia to create an account. (Figure 12)

4. If you are creating an account, fill out the form and click on create your account. (Figure 13)

5. You will receive a welcome message. You can then type a topic of interest you want to contribute to. (Figure 14)

6. Use the (edit icon) to add to or subtract from any part of the content. (Figure 15)

7. Once you are done editing, click on save, and it automatically becomes part of the content on Wikipedia. (Figures 16 and 17) 


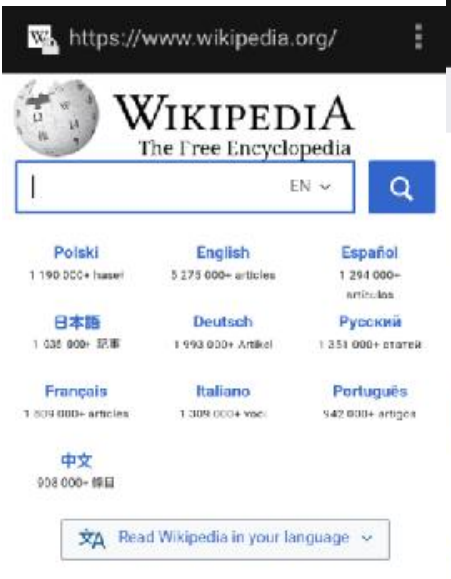

(1)

Wik pedia is hasted by the Wikinedia Foundation, a nonprefit organization that also hosts a range of other prejects.

Figure 11

(Source:

https://www.wikipedia.org

\section{Wh. https://en.m.wikipedia.org/w/ir ;}

$\equiv Q$, Search Wikipedia

Log in

Wikipedia is made by people like you.

Log in to contribute.

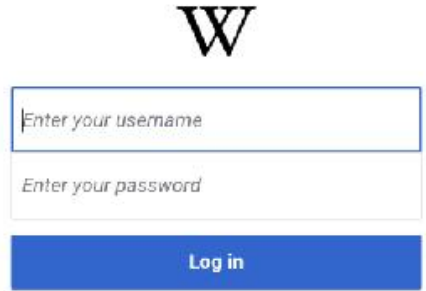

Forgot your password?

Don't have an account?

Join Wikipedia

Join Wikipedia

(Source:

Figure 12

https://en.m.wikipedia.org)
W. https://en.m.wikipedia.org/w/ir

$\equiv a_{\text {Search Wikipedia }}$

Create account

Wikipedia is made by people like you. Log in to contribute.

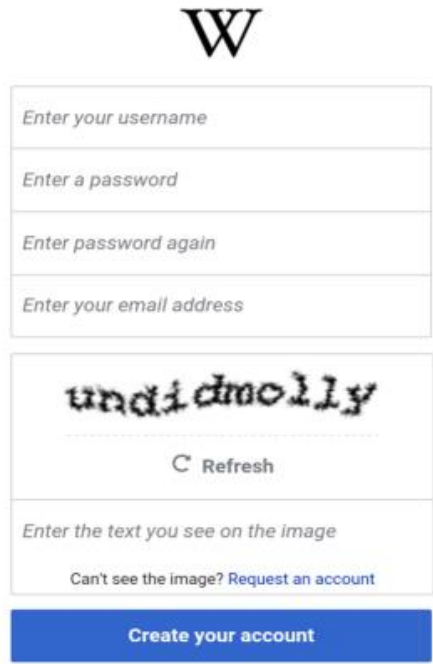

Figure 13

(Source:

https://en.m.wikipedia.org)

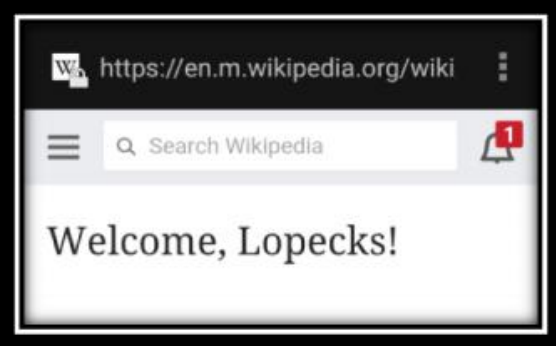

Figure 14

(Source:

https://en.m.wikipedia.org)

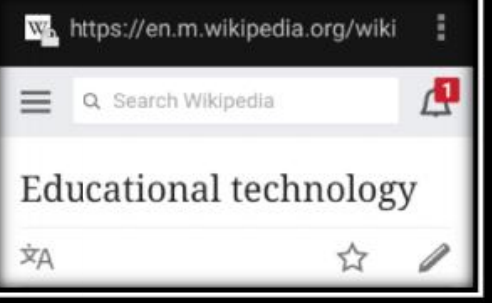

\section{Figure 15}

(Source:

https://en.m.wikipedia.org)

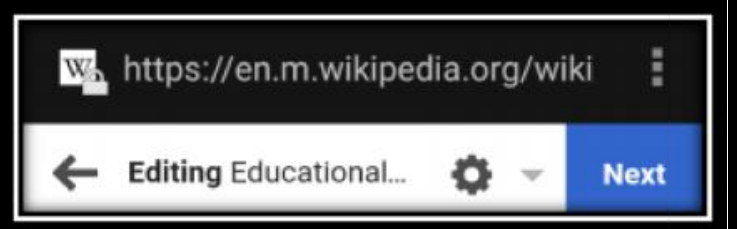

Figure 16

(Source:

https://en.m.wikipedia.org)
Wh https://en.m.wikipedia.org/wiki

Save
Figure 17

(Source:

https://en.m.wikipedia.org) 


\section{Use of Wikis to extend the frontiers knowledge}

There is a saying that the only constant thing is change (Heraclitus, n.d). This is especially true with knowledge. The $21^{\text {st }}$ century is a knowledge economy and has been characterized by changes that have been greatly influenced by technology. Technology has influenced the pace at which information is received. It has equally affected the span of time that a knowledge remains relevant. This is what is referred to as the half-life of knowledge (Gonzalez, 2004), that is the time span from when knowledge is gained till when it becomes obsolete. In tandem with this, knowledge needs to be updated regularly. Knowledge extends when people get to know, accept, create and share information. Therefore, the speed with which knowledge extends is dependent on the access to information, the speed of exchange and the number of sources available to disseminate information. This is where wikis play a role. If an instructor has researched on something new, he could post it on the wiki site. The students and other faculty members who equally have some information on that same topic will equally make their own contributions on the wiki site. As more persons who have information on the topic contribute to the site, they extend the frontiers of knowledge on that particular topic. Thus, as more contributors participate in sharing information on the wiki site, they help in extending the frontiers of knowledge.

\section{CONCLUSION}

The educational process exists to preserve, transfer and expand knowledge and culture. Also, technology exists to ease this process. Technology has come to stay, is growing and providing various tools that can support faculty to enhance teaching/learning and ease the transition from the old paradigm to the new. One of such is Wikis. Wiki is one of the web 2.0 technologies that support collaboration and information sharing which are important for knowledge expansion. But, it happens that the Wiki utilization level of Nigerian faculties is quite low. It therefore becomes necessary for faculty to be aware of what technologies are available and what their affordances are. Once the awareness is gained, the next line of action should be the application based on objectives to be purposeful. Just like other kinds of technology, practice makes the experience better. Faculties should practice how Wikis work and the application will flow seamlessly with other school/class activities.

\section{RECOMMENDATIONS}

Wikis support, anytime - anywhere learning, collaborative learning, social learning, interactive learning and so on. Therefore, the following recommendations are made:

- Faculties should organize training for members on how to create and manage Wikis.

- There should be the creation and utilization of Wiki sites at faculty/departmental levels with active involvement of members.

- Try out Wikis.

\section{REFERENCES}

Akorede, M. D and Okunlaya, O. R., 2015. Investigating the educational use of web 2.0 among undergraduates in Nigerian private universities. Italian Journal of Library and Information Science (JLIS.it) 6(1). Doi: 10.4403/jlis.it.9478.

Eberechi, M. E., 2016. Awareness and use of web 2.0 tools by LIS students at university of Nigeria, Nsukka, Enugu State, Nigeria. Lib. Paper 1355. Retrieved from http://digitalcommons.unLed/libphilprac/1 355.

Foley, B and Chang, T., 2016, April. Wikis as a professional development tool. Paper presented at the American Education Research Association annual meeting, San Francisco, CA.

Gonzalez, C., 2004. The role of blended learning in the world of technology. Retrieved fromhttp://www.unt.edu/benchmarks/arch ives.

Heraclitus (n.d) Heraclitus Quotes. Retrieved from https://www.goodreads.com/author/ quotes/77989. Heraclitus

Ken, R., 2014. The meaning of education collaboration. Retrieved from http://www.connectinglearningtoday.com/ meaning education collaboration. 
Lee, L., 2007. Wikis in plain English. Retrieved from www.commoncraft.com.

Longman Dictionary of Contemporary English Online, 2015. What is collaboration? Retrieved from http://www.Idoceonline.com/dictionary/col laboration

Lori, W., 2016. Internet-based collaboration tools. International Journal of e-collaboration, 12, (1):

Marina, A., 2013. Instructional design for eLearning: Essential guide to creating successfully eLearning courses. Retrieved from www.yourelearningworld. com.
Toffler, A., 1980. The third wave. USA: Bantam Books.

UNESCO., 2002. Information and Communication Technologies in Teacher Education - A planning guide. Division of Higher Education. 